\title{
Spring onsets of a young forest in interior Alaska determined based on time-lapse camera and eddy covariance measurements
}

\author{
Shihori Kawashima ${ }^{a}$, Masahito Ueyama ${ }^{\text {a, }}$, Mikita OKamura ${ }^{a}$, Yoshinobu Harazono, \\ Hiroki IwATA $^{\mathrm{b}}$ and Hideki KOBAYASHI ${ }^{\mathrm{c}}$ \\ $\left(\begin{array}{c}{ }^{\mathrm{a}} \text { Graduate School of Life and Environmental Sciences, Osaka Prefecture University, } \\ 1-1 \text { Gakuen-cho, Naka-ku, Sakai, Osaka 599-8531, Japan } \\ { }^{\mathrm{b}} \text { Department of Environmental Science, Faculty of Science, Shinshu University, 3-1-1 Asahi, Matsumoto, Nagano 390-8621, Japan } \\ { }^{\mathrm{c}} \text { Research Institute for Global Change, Japan Agency for Marine-Earth Science and Technology (JAMSTEC), } \\ 3173-25 \text { Showamachi, Kanazawa-ku, Yokohama, Kanagawa 236-0001, Japan }\end{array}\right)$
}

\begin{abstract}
Spring phenology is essential in modeling the carbon balance of high-latitude ecosystems and is possibly sensitive to climate change. In the present study, we evaluated the onset of the growing season for three species (paper birch, bog blueberry, and bog Labrador tea) in interior Alaska from 2012 to 2019 using photos taken using time-lapse cameras. We also evaluated the onset of the growing season at the ecosystem scale from 2010 to 2019 on the basis of the $\mathrm{CO}_{2}$ flux by the eddy covariance method at the site. On the basis of the growing degree-day (GDD) model with the parameters estimated using the Bayesian approach, we found that the interannual variations in the spring onsets were explained by the model, and the thermal forcing requirement differed among the species. At the ecosystem scale, the spring onset was closely linked to the snow disappearance date. Under the possible future climate scenarios indicated by the representative concentration pathway 8.5 scenario, the spring onsets were predicted to be one to three weeks earlier than the present dates for the three species. The ecosystem-scale onsets were also predicted to be five days to a little over a month earlier at the end of this century. The future spring onset is highly sensitive to the snow disappearance date for high-latitude vegetation; thus, further understanding of climate change before snowmelting is required.
\end{abstract}

Key words: Boreal forest, Ecosystem-scale phenology, Phenology model, Remote sensing, Snow disappearance, Species-scale phenology, Spring warming

\section{Introduction}

Spring phenology is important in modeling the carbon balance of high-latitude ecosystems and is possibly sensitive to climate change (Myneni et al., 2001; White et al., 1999). Satellite remote sensing data indicate that the onset of the growing season became 0.32 days $\mathrm{yr}^{-1}$ earlier at $40^{\circ}$ northward in North America from 1982 to 2005 (Zhang et al., 2007). These changes are possibly caused by ongoing high-latitude warming (Piao et al., 2020). Despite its importance, the spring phenology of high-latitude vegetation is not fully understood (Jarvis and Linder, 2000; Suni et al., 2003), resulting in considerable uncertainties in predictions of the future carbon cycle (Euskirchen et al., 2006; Holmberg et al., 2019).

Time-lapse cameras are useful for monitoring vegetation phenology at the species and ecosystem scales (Ide and Oguma, 2010; Keenan et al., 2014; Kobayashi et al., 2016; Nagai et al., 2013; Xie et al., 2018). Time-lapse cameras allow us to monitor

Received; January 11, 2021

Accepted; March 10, 2021

†Corresponding author: ueyama@envi.osakafu-u.ac.jp

DOI: 10.2480/agrmet.D-21-00003

(C) Author (s) 2021.

This is an open access article under the CC BY 4.0 license. phenology at smaller spatiotemporal scales than those monitored by satellite remote sensing and thus can be useful for filling the gap between satellite and field observations. The onset of the growing season as determined by camera observations was consistent with that detected by visual inspection at a site (Keenan et al., 2014), which was linearly related to the canopy leaf area index. Despite the wide availability of data, limited studies have used cameras for phenological studies in high-latitude vegetation (Kobayashi et al., 2016; Nagai et al., 2013). Previous studies revealed that the interannual variations in the spring onsets were controlled by spring temperatures at the ecosystem scale on the basis of analyses using camera images (Ide and Oguma, 2010; Kobayashi et al., 2016), but few studies analyzed such variations at the species scale (Xie et al., 2018).

Eddy covariance measurements provide information on ecosystem-scale phenology. Previously, the $\mathrm{CO}_{2}$ fluxes observed by the eddy covariance method were used to understand the mechanism of spring and autumn phenological transitions in 21 global forests (Richardson et al., 2010) and 29 forests (Melaas et al., 2013). Melaas et al. (2013) found that the growing degree days (GDD) model could be useful to predict the spring onset of gross primary productivity (GPP) after considering the geographic variability in the photoperiod and thermal forcing accumulation required for spring onset. In boreal forests, Suni et al. (2003) evaluated the importance of five-day running air temperature for spring onsets on the basis of $\mathrm{CO}_{2}$ fluxes 
using eddy covariance data. On the basis of eddy covariance measurements in three boreal forests, Barr et al. (2009) also found that soil thaw was an important driver of spring onset and that spring temperature primarily controlled annual production. In boreal forests, few studies have evaluated spring onset using both ecosystem-scale data from eddy covariance measurements and species-scale data from cameras. The use of both datasets could help us better understand each other's results. Boreal forests often have an open canopy structure, and the contributions of understories to $\mathrm{CO}_{2}$ exchange are important (Ikawa et al., 2015). Thus, it is important to understand the spring onset of overstory and understory species as well as those at the ecosystem scale.

In this study, our objective is to quantify the temperature sensitivity of spring phenology at a young forest in interior Alaska. Toward the goal, we evaluated the spring onsets of individual species by camera images and ecosystem-scale $\mathrm{CO}_{2}$ fluxes with eddy covariance measurements in a young forest in interior Alaska. Then, we explained the interannual variability in the onset for each species and ecosystem-scale $\mathrm{CO}_{2}$ fluxes. The variability in the onset was evaluated on the basis of the GDD model with the parameters determined by the Bayesian approach. Finally, we predicted the spring onset at the end of this century. We discuss important environmental variables, such as air temperature and snow disappearance date, in future modeling activities for high-latitude regions.

\section{Materials and methods}

\subsection{Study area}

The study site was a young forest after a wildfire in the Poker Flat Research Range in interior Alaska, USA $\left(65^{\circ} 07^{\prime} 11 " \mathrm{~N}\right.$, $147^{\circ} 25^{\prime} 44^{\prime \prime} \mathrm{W}$, altitude $491 \mathrm{~m}$; hereinafter referred to as the US-Rpf site of AmeriFlux code; Ueyama et al., 2019). The US-Rpf site was a burned black spruce forest after the wildfire continued from late June to early August 2004, where shrubs (e.g., blueberry and Labrador tea) and deciduous broad-leaved trees (e.g., paper birch, aspen, and willow) had regenerated by the time of observation. The deciduous trees grow in the upper layer, whereas evergreen trees (black spruce), herbaceous plants, and mosses (e.g., juniper hair cap) grow in the lower layer. At the site from 2010 to 2019 , the mean annual air temperature ranged from $-2.6^{\circ} \mathrm{C}$ to $1.3^{\circ} \mathrm{C}$, and the annual rainfall ranged from $231 \mathrm{~mm} \mathrm{yr}^{-1}$ to $516 \mathrm{~mm} \mathrm{yr}^{-1}$. The snow disappearance date was generally observed from the end of April to the middle of May. Further details on the study site were available for $\mathrm{CO}_{2}$ flux (Iwata et al., 2011; Ueyama et al., 2019), energy flux (Ueyama et al., 2020), and leaf photosynthetic characteristics (Ueyama et al., 2018).

\subsection{Meteorological observations}

We used meteorological and eddy covariance data from 2010 to 2019 (Ueyama et al., 2019). We briefly describe the measurement system used in this study. Air temperature was measured at $1 \mathrm{~m}$ above the ground using a temperature and humidity sensor (HMP45, Vaisala, Finland) mounted in a ventilated radiation shield. Downward and upward shortwave radiations were measured using pyranometers (PCM-01, CMP3, and CNR4, Kipp \& Zonen, Netherlands). $\mathrm{CO}_{2}$ flux was measured by the eddy covariance method using several types of sonic anemometers and gas analyzers. Intercomparisons between observation systems were conducted, and systematic differences were adjusted (Ueyama et al., 2019). The meteorological and turbulence data were collected using a data logger (CR3000, Campbell Scientific Inc., USA).

Net ecosystem exchange (NEE) was calculated by accounting for a storage change determined from the concentration at the height of eddy covariance observation. The artificial negative $\mathrm{CO}_{2}$ flux measured by the open-path gas analyzer (LI-7500, Li-Cor, USA) was corrected on the basis of Amiro (2010). The correction was not applied for the new analyzer (EC150, Campbell Scientific Inc., USA) (Helbig et al., 2016). Further details for the observations and data processing are shown in Ueyama et al. (2019).

We also used the precipitation from the closest weather station at Fairbanks International Airport, Alaska (40 km apart from the site) from 2010 to 2019 by the National Climatic Data Center.

\subsection{The time-lapse camera observation and data analysis}

We used the photos taken by the GardenWatchCam time-lapse camera (Brinno, Taiwan; resolution of $1280 \times 1040 \mathrm{px}$ ) from 2010 to July 2016 and the TLC2000 time-lapse camera (Brinno, Taiwan; resolution of $1280 \times 720$ px) from July 2016 to 2019 . The former cameras were mounted horizontally at a height of $1 \mathrm{~m}$. The latter cameras were mounted at heights from $2 \mathrm{~m}$ to $6 \mathrm{~m}$ facing down to the ground depending on the vegetation regrowth. Photos were taken every hour during the daytime using an automatic white balance. We extracted the region of interest from the photo where one species dominated, for each species (Fig. 1). The color digital values of red (R), green (G), and blue (B) in the region of interest were averaged and then used to calculate the green color index $g_{c c}$ : the relative proportion of $\mathrm{G}$ to the sum of R, G, and B (Harazono et al., 2009; Keenan et al., 2014; Xie et $a l ., 2018)$. To reduce artificial fluctuations in $g_{c c}$ due to different brightness values in different weather conditions, the median $g_{c c}$ was extracted from a 3-day moving window for each day.

We used $g_{c c}$ data after the snow disappearance date because the onset of the growing season for each species occurred after the snow disappeared. The snow disappearance date was determined as the date when the measured albedo was continuously less than the typical growing-season albedo at this site (0.15). We estimated the date of spring budburst or greening for the three species using time-lapse camera images. We used the definition of the spring onset on the basis of the so-called threshold method according to Xie et al. (2018). The spring onset was determined as the first day when $g_{c c}$ normalized with the seasonal maximum value successively exceeded 0.05 in the period from the snow disappearance date to the end of July.

\subsection{Study species}

We investigated the spring onsets of paper birch (Betula papyrifera), bog blueberry (Vaccinium uliginosum), and bog Labrador tea (Ledum groenlandicum) on the basis of camera images. The paper birch is classified as deciduous broad-leaved trees, and bog blueberry is classified as a deciduous understory. Bog Labrador tea is an evergreen understory species but showed obvious greening in the spring and browning in the autumn. 
(a)

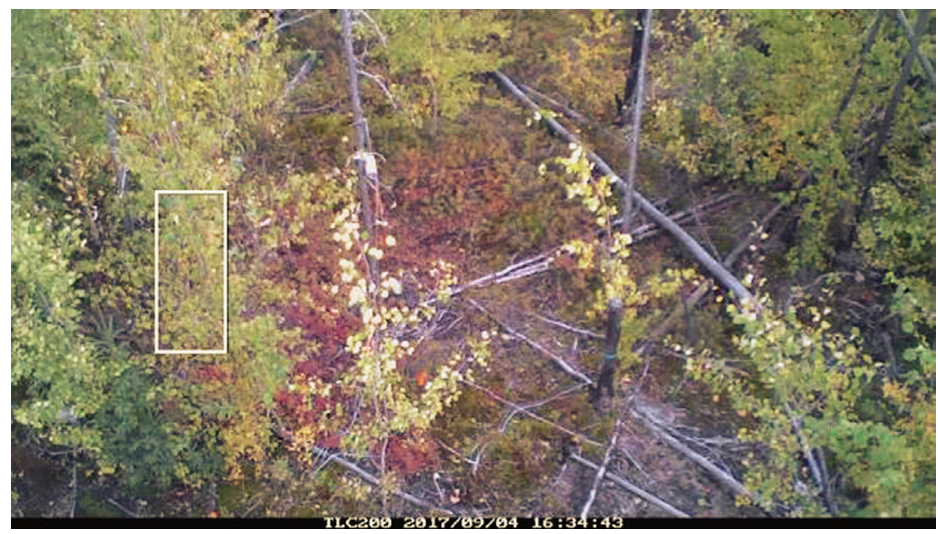

(b)

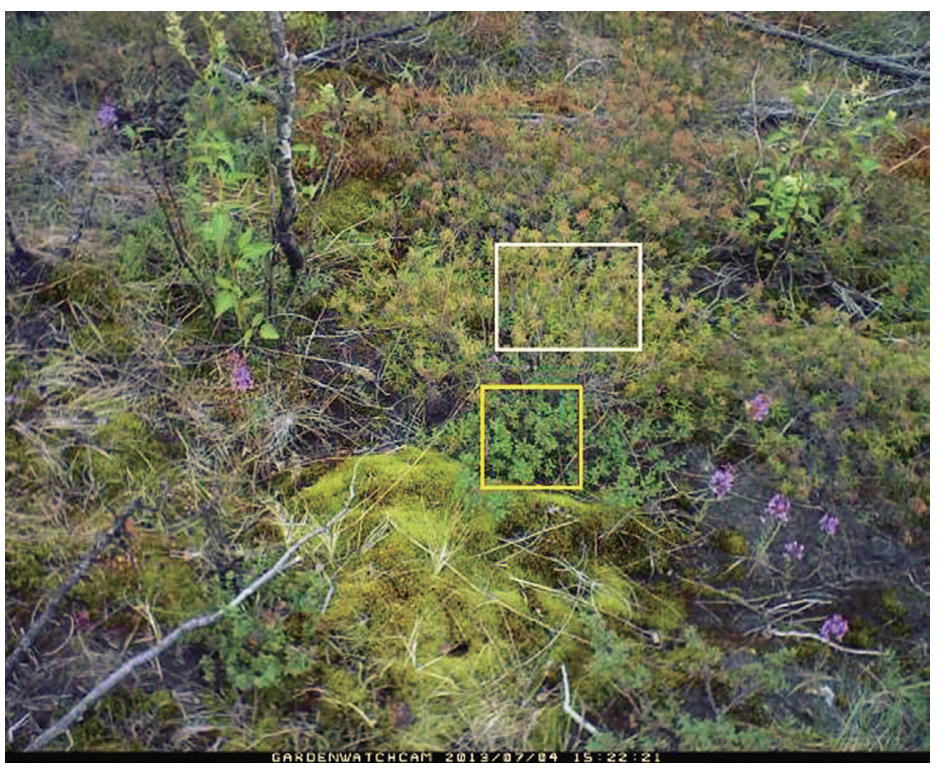

Fig. 1. Examples of the region of interest in the camera image. The image taken by the TLC200 time-lapse camera on September 4, 2017, and the region of interest for paper birch are shown in the white frame (a). The image taken by the GardenWatchCam time-lapse camera on July 4, 2013, and the regions of interest for bog Labrador tea (white frame) and bog blueberry (yellow frame) are shown (b).

Because of the data availability, the study period and sample size differed in the species. The camera images for the paper birch were available for one sample in 2012, 2013, and 2017, two samples in 2018, and three samples in 2019. Images of bog blueberries were available for one sample in 2013, 2014, 2015, and 2018. The images of bog Labrador tea were available for one sample in 2012, 2013, 2014, and 2015. Samples used for one species varied from year to year.

\subsection{Data analysis for each species}

We used the GDD model (Cannell and Smith, 1983; Leinonen and Kramer, 2002; Melaas et al., 2013) to explain the onset of the growing season for each species. In the model, the onset was determined as the day when GDD exceeded the cumulative temperature required for spring onset $\left(G D D_{c}\right.$; hereinafter referred to as the thermal forcing requirement). The GDD on a given day $\left(t_{1}\right)$ was calculated by cumulating the mean air temperature above a degree-day base temperature $\left(T_{b}\right)$ after the day on which accumulation started $\left(t_{0}\right)$. We set the starting date $\left(t_{0}\right)$ as the snow disappearance date. Although chilling requirement in winter is essential for spring onset in the temperate region (Ettinger et al., 2020), it could be easily met under long and cold winter in interior Alaska; hence, we did not consider the chilling requirement in this study.

We determined two parameters $T_{b}$ and $G D D_{c}$ for each species using the same data with the differential evolution method (Das and Suganthan, 2010) in a preliminary experiment. Based on the experiment, the $T_{b}$ varied little among the three species, where the $T_{b}$ was estimated as $0.3^{\circ} \mathrm{C}$ for paper birch, $1.8^{\circ} \mathrm{C}$ for bog blueberry, and $0.3^{\circ} \mathrm{C}$ for bog Labrador tea, and the $G D D_{c}$ was estimated as $42.7^{\circ} \mathrm{C}$ days for paper birch, $15.9^{\circ} \mathrm{C}$ days for bog blueberry, and $25.5^{\circ} \mathrm{C}$ days for bog Labrador tea. Hence, we fixed $T_{b}$ for all species to the lowest $T_{b}, 0.3^{\circ} \mathrm{C}$, and determined only $G D D_{c}$ that varied greatly among the three species to minimize equifinality in the parameterization. We estimated the probability density distributions of $G D D_{c}$ using a constraint of observed $g_{c c}$-based spring onset on the basis of the Bayesian approach using the library PyMC3 (Version 3.7) in Python. We determined the posteriori distributions of the parameter from the initial maximum posterior probability using the Metropolis-Hasting method. In the parameterization, we used 10,000 samples after 1,000 samples of warm-up and then evaluated the $95 \%$ Bayesian highest posterior density (HPD) intervals to identify uncertainties in the parameter. 


\subsection{Data analysis for the ecosystem scale}

We determined the onset of the growing season for NEE or GPP to explain the onset at the ecosystem scale. We used the gap-filled NEE and GPP from 2010 to 2019, where the data gap was filled using a combined look-up-table method and nonlinear regression method (Ueyama et al., 2019). GPP was partitioned from NEE on the basis of a nighttime approach using the Flux Analysis Tool program version 2.0 (Ueyama et al., 2012). The onset of NEE was determined as the date when the seven-day moving mean NEE continuously showed negative values. The

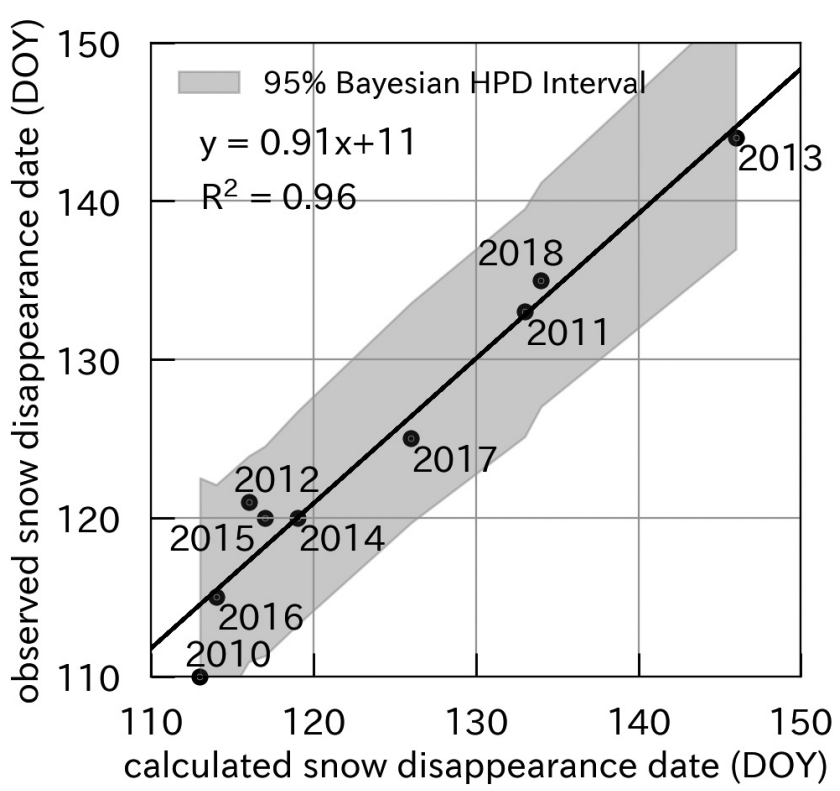

Fig. 2. A comparison between the calculated and observed snow disappearance dates. The calculated snow disappearance date was based on the snow model (Ito and Inatomi, 2012). The observed snow disappearance date was the date when the albedo at the site was continuously less than 0.15 . The solid line indicates the linear regression based on a mean of the Bayesian samples, and the shading indicates the $95 \%$ Bayesian highest posterior density (HPD) interval. The number near the plot indicates the year of observation. onset of GPP was the date when the seven-day moving mean GPP was continuously higher than $10 \%$ of its annual amplitude (Melaas et al., 2013).

We applied a linear regression to explain the onsets of GPP and NEE using the snow disappearance date because the onsets were linearly correlated with the snow disappearance date (shown in section 3.3). We did not apply the GDD model to explain the ecosystem-scale onsets because 1) the onsets occurred earlier than the snow disappearance date but 2) the parameter $\left(t_{0}\right)$ was set as the snow disappearance date. We determined the linear regression based on the Bayesian approach with a no-U turn sampler. In the parameterization, we used 2,000 samples and then evaluated the 95\% Bayesian HPD intervals.

\subsection{Future predictions of spring onsets}

We predicted the future spring onsets for each species, NEE, and GPP from 2010 to 2099 under the representative concentration pathway (RCP) 8.5 scenario. We chose the RCP8.5 scenario because our aim was to evaluate the possibility when global warming was the most severe. We used simulated climate data for the selected pixel for the study site, which included the predicted air temperature and precipitation, on the basis of five climate models (HadGEM2-ES, IPSL-CM5A-LR, MIROC-ESM-CHEM, GFDL-ESM2M, and NorESM1-M) produced in the Coupled Model Intercomparison Project 5 (Hempel et al., 2013). In the climate data, the mean air temperatures were $2.4^{\circ} \mathrm{C}-7.7^{\circ} \mathrm{C}$ higher in the $2090 \mathrm{~s}$ than in the 2010 s, whereas the annual precipitation was $55-157 \mathrm{~mm} \mathrm{yr}^{-1}$ larger. We predicted the snow disappearance date using the snow model embedded in a terrestrial ecosystem model, VISIT (Ito and Inatomi, 2012), by inputting the climate forcing. The snow model estimates the snow water equivalent at the daily timestep using air temperature and precipitation. We found that the model accurately estimated the snow disappearance dates at the site from 2010 to 2018 (Fig. 2).

\section{Results}

\subsection{Spring onset based on $\boldsymbol{g}_{c c}$ for each species}

The $g_{c c}$ for the three species increased after snowmelt in the spring (Fig. 3), reflecting the onset of the growing season.



Fig. 3. Normalized daily $g_{c c}$ for each species from day of year (DOY) 115 to 213 in 2014 (a) and 2018 (b). The vertical dashed lines indicate the snow disappearance date. The horizontal dashed lines show $5 \%$ of the maximum $g_{c c}$ for each species. 
This result was caused by the budburst in paper birch and bog blueberry and by the greening of the leaves of bog Labrador tea. The background of the target plant, such as the forest floor, had little influence on the spring increase in $g_{c c}$ because we did not analyze plants whose background color changed significantly (Fig. 1). The timing of the onset due to the increasing $g_{c c}$ differed among the species. Bog Labrador tea started greening earliest, and the budburst of paper birch and bog blueberry followed. The different onsets represented the species-specific response to environmental conditions during the spring. Duplicated samples of the onset ( $n=2$ or 3 ) were collected for only paper birch in individual years, showing that the difference in the onset among samples was up to three days within a year.

\subsection{Parameterization of the GDD model for each species}

We found that the interannual variations in the spring onset were well explained by the GDD model $\left(R^{2}=0.71\right.$; $\mathrm{p}<0.05$ for paper birch, $\mathrm{R}^{2}=0.65 ; \mathrm{p}<0.05$ for bog blueberry, $\mathrm{R}^{2}=0.87 ; \mathrm{p}<0.05$ for bog Labrador tea), and the thermal forcing requirements differed among the species. The mode and 95\% Bayesian HPD intervals of the thermal forcing requirements were estimated to be $17.7(2.5-40.8)^{\circ} \mathrm{C}$ day for bog Labrador tea, $70.0(51.5-80.4)^{\circ} \mathrm{C}$ day for paper birch, and $156.0(116.8-193.0)^{\circ} \mathrm{C}$ day for bog blueberry (Fig. 4). These intervals showed significant differences in the parameters among the species.

The GDD model reproduced the interannual variations in the observed onset for each species (Fig. 5). The earliest onset in 2016 was explained by the warmest air temperature in May $\left(9.7^{\circ} \mathrm{C}\right)$, and the latest onset in 2013 was explained by the coldest temperature in May $\left(4.2^{\circ} \mathrm{C}\right)$ for all three species. The $95 \%$ Bayesian HPD intervals of the root-mean-square error were up to 3.9 days for bog Labrador tea, up to 2.7 days for paper birch, and up to 4.4 days for bog blueberry.

The GDD model generally reproduced the interannual variations in the observed onset for each species (Fig. 5). The respective standard deviations of the observed and calculated onsets were 5.4 and 5.2 days (5.0-5.5 days) for paper birch, 7.5 and 8.8 days (8.4-9.3 days) for bog blueberry, and 11.2 and 10.5 days (10.0-11.0 days) for bog Labrador tea, where the values in the calculated onsets were the mean and the

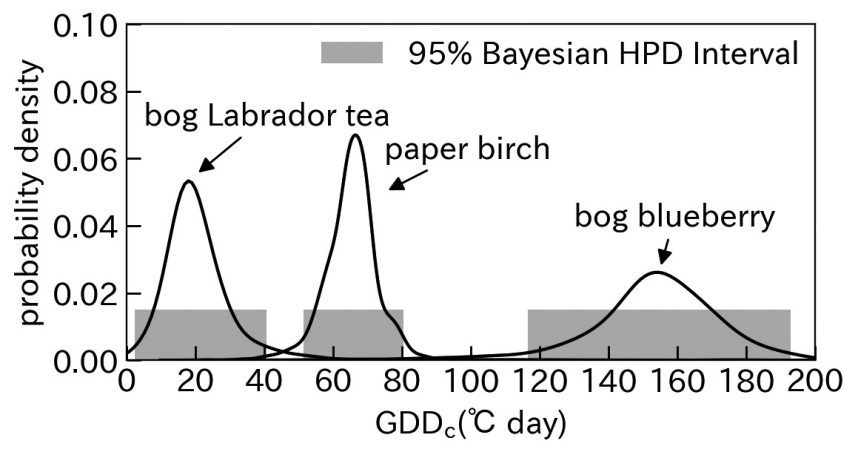

Fig. 4. Estimated posterior probability density distributions of the effective cumulative temperature for the three species. The gray bar drawn on the horizontal axis indicates the 95\% Bayesian highest posterior density (HPD) interval.

95\% Bayesian HPD interval. The interannual variability was consistent for paper birch and was slightly overestimated or underestimated for the other species. The interannual variability was smallest for paper birch, followed by bog blue berry and then bog Labrador tea, which were well reproduced by the model. Generally, all species basically showed synchronized interannual variations at spring onset. On the basis of a linear regression between mean air temperature from mid-April to May and the spring onset, we estimated the temperature sensitivity in the spring onset in terms of the interannual variations. The estimated sensitivity of the spring onset to air temperature from mid-April to May was -1.9 days ${ }^{\circ} \mathrm{C}^{-1}$ for paper birch, -1.8 days ${ }^{\circ} \mathrm{C}^{-1}$ for bog blueberry, and -2.9 days ${ }^{\circ} \mathrm{C}^{-1}$ for Labrador tea.

\subsection{Spring onset for the ecosystem scale}

The onset of the growing season for NEE and GPP was positively correlated with the snow disappearance date (Fig. 6). The linear regression for the onset of NEE had a slope of 0.89 days day ${ }^{-1}\left(0.29-1.47\right.$ days day $\left.^{-1}\right)$ and an intercept of 9 days $(-64-83$ days $)\left(R^{2}=0.70\right)$, where the range shown in parentheses represents the 95\% Bayesian HPD interval. The regression for GPP had a slope of 0.84 days day $^{-1}$ $\left(0.39-1.21\right.$ days $\left.^{-1 a y}{ }^{-1}\right)$ and an intercept of 18 days ( $-32-71$ days) $\left(\mathrm{R}^{2}=0.87\right)$. These regressions suggest that the snow disappearance date and the onset of the $\mathrm{CO}_{2}$ fluxes are closely

(a) paper birch

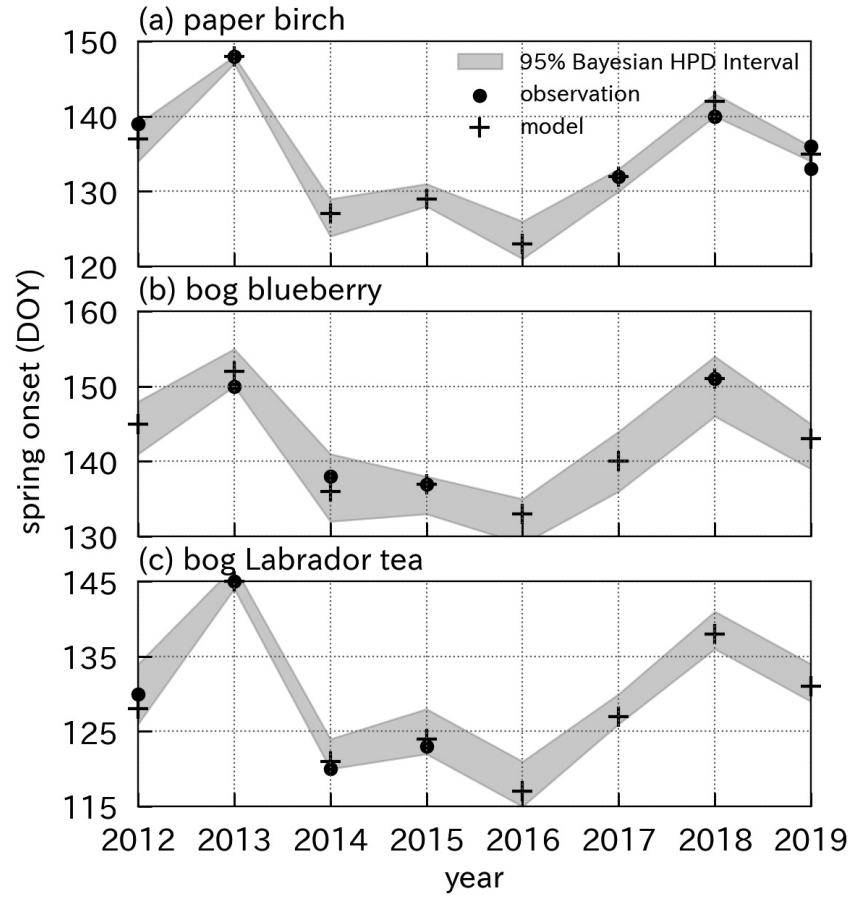

Fig. 5. Interannual variations in the calculated and observed spring onsets for paper birch (a), bog blueberry (b), and bog Labrador tea (c) from 2012 to 2019 . The gray shadows indicate the $95 \%$ Bayesian highest posterior density (HPD) interval by the growing degree days model. The cross plots indicate the mode by the model that has a different parameter, whereas the black plots indicate the observation. Note that two samples for paper birch showed the exactly same spring onset in 2018; two of the three samples showed the spring onset as DOY 136 in 2019. 
linked to each other. The onset of the $\mathrm{CO}_{2}$ fluxes occurred earlier than those for the deciduous species paper birch and bog blueberry (Fig. 7). The sensitivity of the ecosystem-scale onset to air temperature from mid-April to May was -3.5 days ${ }^{\circ} \mathrm{C}^{-1}$ for NEE and -3.0 days ${ }^{\circ} \mathrm{C}^{-1}$ for GPP. The similar relationships for NEE and GPP indicate small variability in ecosystem respiration in the spring.

The contributions of GPP before budburst of birch to the annual GPP were negatively correlated with the mean air temperature in May (Fig. 8). We calculated the contributions as a ratio of GPP before the budburst of birch (Fig. 5a) to the annual GPP. The contributions varied each year, ranging from $38.6 \%$ in the cold year (2013) to $7.8 \%$ in the warm year (2019), showing that a cooler spring induced higher contributions of understory in the spring, but a warmer spring caused lower contributions $\left(-5.2 \%{ }^{\circ} \mathrm{C}^{-1} ; \mathrm{R}^{2}=0.91\right)$.

\subsection{Future predictions of the spring onset}

Under the RCP8.5 scenario, the spring onset for the three species was predicted to be one to three weeks earlier at the end of this century (Fig. 9a). The advanced onset in the future was predicted to be 17.8 days (8.0-24.1 days) for paper birch, 18.1 days (8.1-22.3 days) for bog blueberry, and 18.1 days (7.9-27.3 days) for bog Labrador tea; the mean and the 95\% confidence interval were estimated by considering the uncertainties in the determined parameter and climate change simulations. Because of the large variabilities in the climate by the different models, the differences in the advanced onset were not clear among the species.

The advanced spring onset for the three species was predicted to occur due to earlier snow disappearance because the snow disappearance date was estimated to be 7.8-33.7 days earlier based on the snow model (Fig. 10). By contrast, the days required for accumulating thermal forcing did not substantially change under the scenarios. The mean and 95\% confidence interval of the days for accumulating thermal forcing were predicted to be -1.4 days $(-6.8-2.2$ days) for paper birch, -0.9 days $(-7.9-3.7$ days $)$ for bog blueberry, and -0.9 days $(-4.2-1.4$ days $)$ for bog Labrador tea.

The spring onset at the ecosystem scale was predicted to
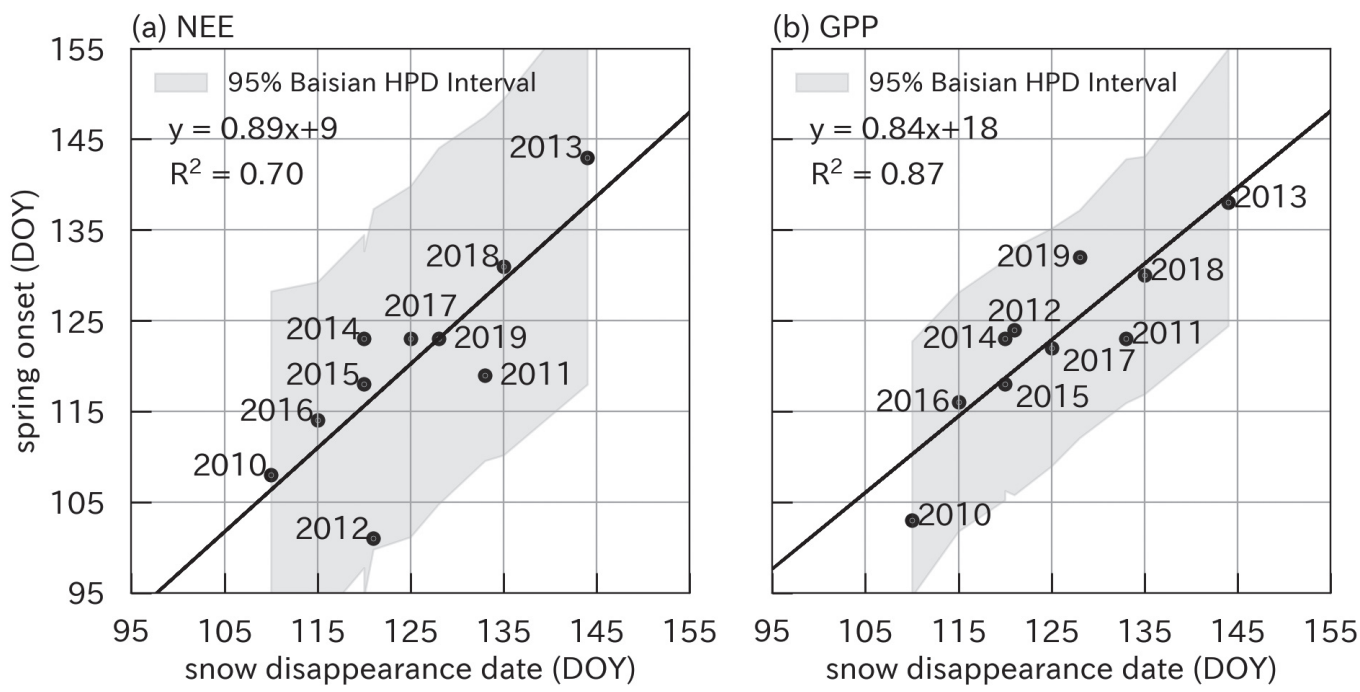

Fig. 6. Relationship of the snow disappearance date to the onset of the growing season for net ecosystem exchange (NEE) (a) and gross primary productivity (GPP) (b) from 2011 to 2019 . The solid line indicates the linear regression based on a mean of the Bayesian samples, and the shading indicates the $95 \%$ Bayesian highest posterior density (HPD) interval. The number near the plot indicates the year of observation.

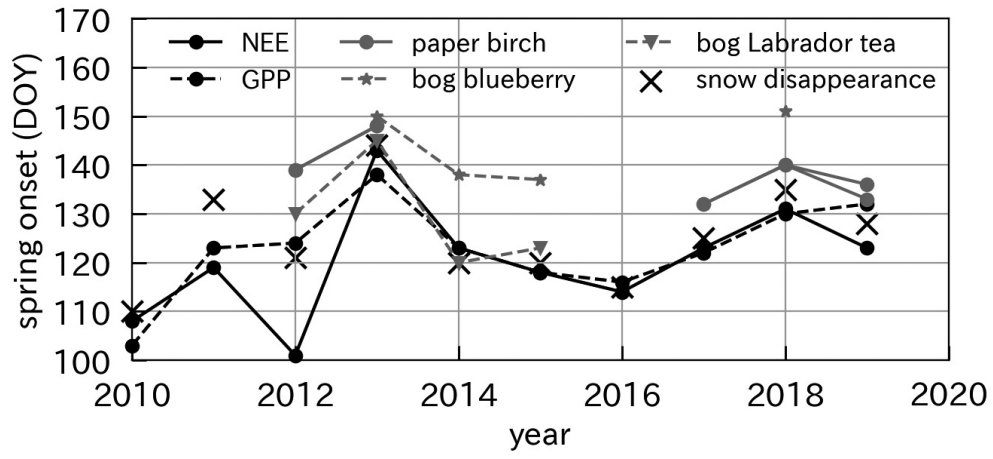

Fig. 7. Interannual variations in the observed spring onsets for three species and those for NEE and GPP, and the snow disappearance date from 2010 to 2019. 


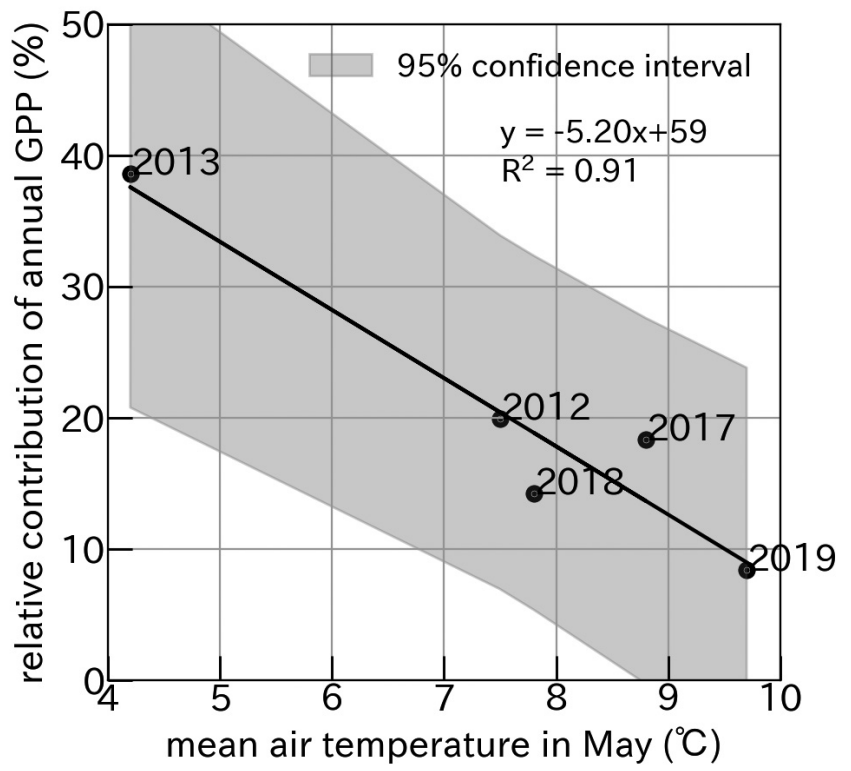

Fig. 8. Relationship of the mean air temperature in May to the relative contribution of the GPP before the budburst of birch trees to the annual GPP (the percentage of GPP when the buds of paper birch burst to annual GPP). The solid line indicates the regression line, and the shading indicates the 95\% confidence interval. The number near the plot indicates the year of observation.

(a)
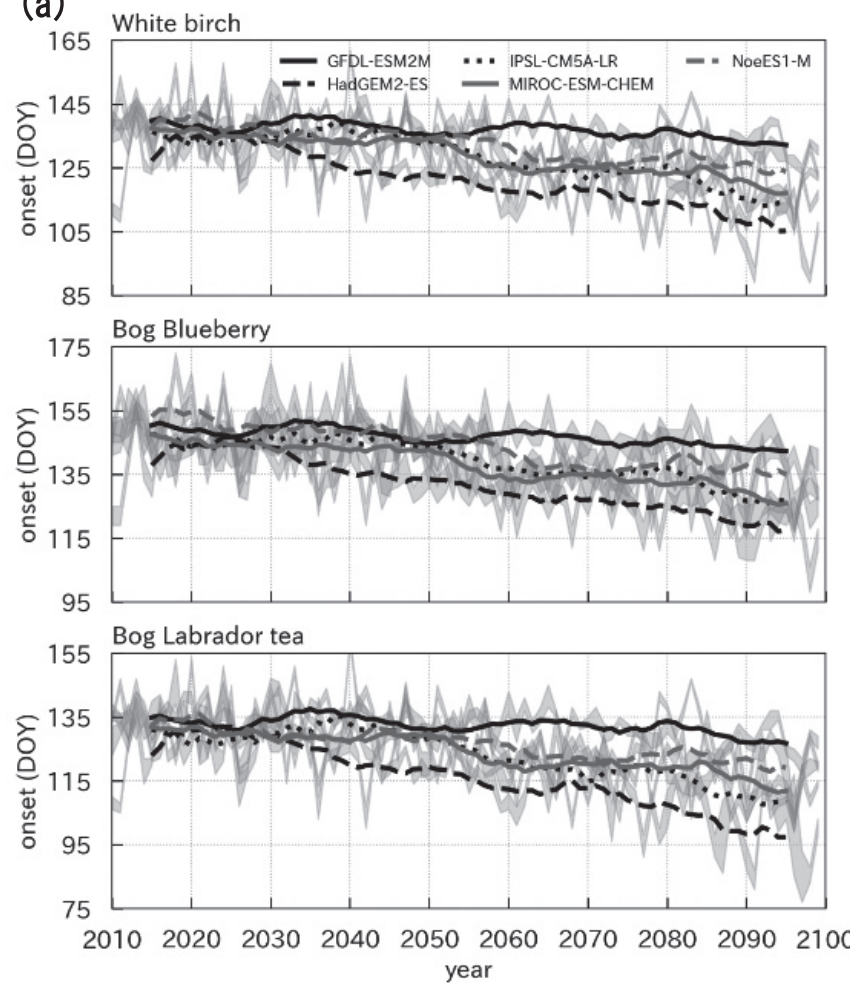

be five days to a little over a month earlier at the end of this century under all RCP8.5 scenarios (Fig. 9b). Considering the uncertainty in the climate simulations, the mean and $95 \%$ confidence interval of the spring onset were predicted to be 18.7 days (5.6-38.6 days) for NEE and 16.4 days (4.9-34.3 days) for GPP. This earlier onset was predicted because of the earlier snow disappearance because the onset at the ecosystem scale was explained through the linear regression using the snow disappearance date (Fig. 6). The advancements for the ecosystem-scale onset were similar to those for each species (Fig. 9a).

\section{Discussion}

The combination of a time-lapse camera with $g_{c c}$ was a useful approach for determining the species-specific onset of the growing season (Fig. 3). The $g_{c c}$ was previously used to evaluate ecosystem-scale phenology (Ide and Oguma, 2010; Keenan et al., 2014; Kobayashi et al., 2016) and species-specific phenology (Xie et al., 2018) and to estimate $\mathrm{CO}_{2}$ flux (Ahrends et al., 2009; Harazono et al., 2009; Ide et al., 2011; Ueyama et al., 2013). Since the $\mathrm{CO}_{2}$ balance in boreal forests is often contributed by not only overstory vegetation but also understory vegetation (Ikawa et al., 2015), the species-specific phenological onset for both overstory and understory species could be useful for understanding the $\mathrm{CO}_{2}$ balance in boreal forests. (b)

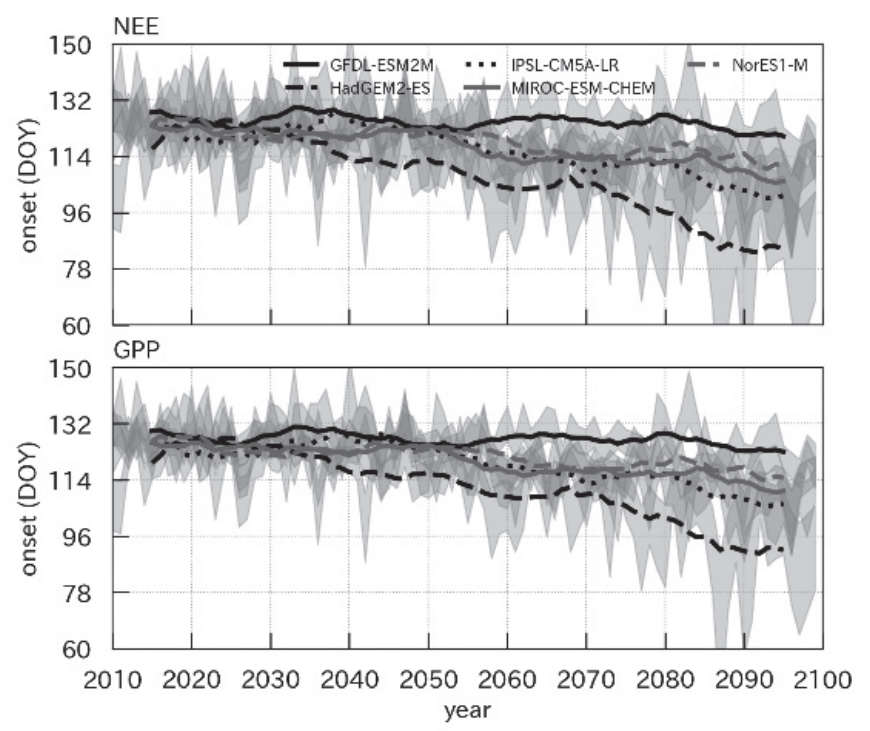

Fig. 9. Spring onsets from 2010 to 2099 for the three species (a) and for net ecosystem exchange (NEE) (b) and gross primary productivity (GPP) (b) based on future climate predicted using five climate models (HadGEM2-ES, IPSL-CM5A-LR, MIROC-ESM-CHEM, GFDL-ESM2M, and NorESM1-M) under the representative concentration pathway (RCP) 8.5 scenario. The lines in (a) indicate the 10 year moving mean of the mode by the growing degree days model for the three species. The lines in (b) indicate the 10 year moving mean of the mean of the Bayesian samples for NEE and GPP. The shading indicates the 95\% Bayesian highest posterior density (HPD) interval. 


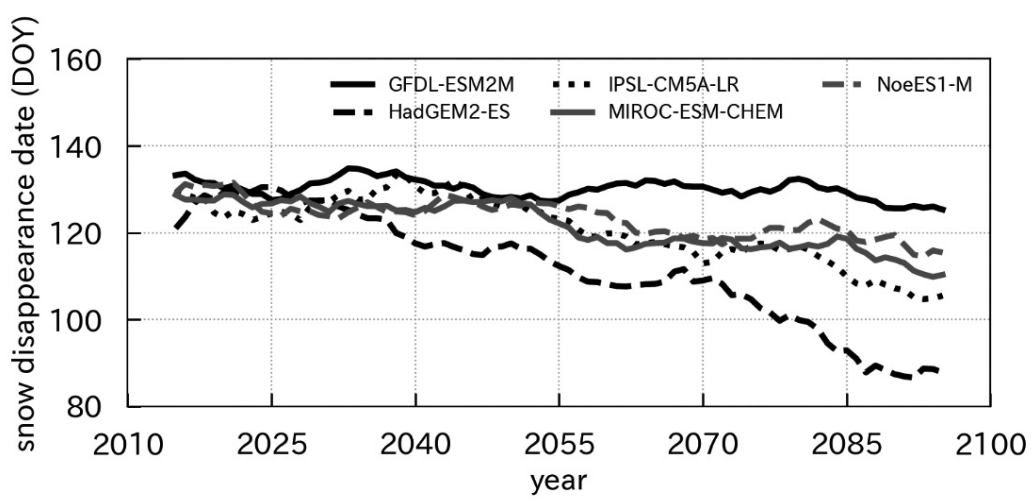

Fig. 10. The future snow disappearance date from 2010 to 2099 predicted using five climate models (HadGEM2-ES, IPSL-CM5A-LR, MIROC-ESM-CHEM, GFDL-ESM2M, and NorESM1-M) under the representative concentration pathway (RCP) 8.5 scenario. The predicted snow disappearance date was the first date when the snow disappeared in each year.

The GDD model successfully explained the spring onset for the boreal species (Fig. 5). We confirmed that the species-scale onsets determined by the GDD model were better reproduced than those determined by the regression using the snow disappearance date. The onsets for the three species were well regulated by air temperature after snowmelt (Fig. 5), meaning that warming could similarly influence the onsets of the three species (Fig. 9a). Photoperiod could have little effect on the onsets at this site because photoperiod around the spring onset at this site is longer than previously reported requirements (9.6-10.5 h) for boreal deciduous forests (Melaas et al., 2013). Despite the simple structure, the GDD model was used to successfully evaluate spring onset in various plants (Vitasse et al., 2011) and eddy covariance-based fluxes (Melaas et al., 2013). The good performance of the model was reported for high-latitude ecosystems on the basis of a satellite-based regional-scale study (Fu et al., 2014a).

The ecosystem-scale spring onset was closely linked to the snow disappearance date (Fig. 6) and was earlier than that for the deciduous species (Fig. 7). This difference was possibly because evergreen shrubs including black spruce seedlings and mosses could start photosynthesis during and immediately after snowmelt at the study site. After snowmelt, surface soils $(\sim 10 \mathrm{~cm}$ depth) immediately thawed and reached above-zero temperatures. The onset of plant productivity is known to be linked to liquid water availability, which is related to the presence of above-zero soil temperatures (Jarvis and Linder, 2000). Hence, the ecosystem-scale onset was sensitive to snowmelt, which determines energy loading into soils and light availability for shrubs and mosses. This result indicated that the ecosystem-scale onset was determined by the meteorological conditions in late winter. Conversely, the onset for deciduous species was regulated by cumulating air temperature after snowmelt. The species-scale onset was determined by the snow disappearance date and air temperature after snowmelt. Since disappearing snow increases net radiation and regional air temperatures (Ueyama et al., 2020), the warming rate before and after snowmelt could differ even under similar forcing changes. This result indicated that the prediction of species-scale onsets could be more complex than that of ecosystem-scale onsets. Hence, the different sensitivities of the species- and ecosystem-scale onsets could be essential in the boreal $\mathrm{CO}_{2}$ balance.

The warming spring temperatures could regulate photosynthesis in the understory due to low light availability during the early spring. In the period between snowmelt and budburst in the future, daily incoming solar radiation will decrease and day length will shorten because the period will move forward from summer solstices. After the expected earlier budburst of overstory vegetation, light availability for the understory will be reduced for the rest of the growing season. This phenomenon could result in decreased contributions of understory productivity into the warmer spring (Fig. 8).

The advanced future onset of the growing season was consistent with those predicted by land surface models and field-based estimates. Holmberg et al. (2019) predicted the earlier onset of boreal regions at the end of the 21 st century by approximately three weeks using the model. Euskirchen et al. (2006) predicted 43.4 days longer growing seasons in boreal and Arctic regions from 1976 to 2100 on the basis of the model, mostly due to the earlier spring onset. Based on our study, the predicted future sensitivity (28.4 days advancement under a $1.6-7.2^{\circ} \mathrm{C}$ increase; hence, up to 3.9 days per degree Celsius) was consistent with those estimated on the basis of trans-Alaska camera analysis $\left(-2.5\right.$ to -3.9 days ${ }^{\circ} \mathrm{C}^{-1}$; Kobayashi et al., 2016). On the basis of the sensitivity by Kobayashi et al. (2016) with the RCP8.5 climate scenario, the spring onset was roughly assumed to be a week to a month earlier in the boreal region at the end of this century, which is similar to our estimates.

We found that snow disappearance is an essential process for determining future spring onset for boreal forests. The earlier onset could accelerate GPP and $\mathrm{CO}_{2}$ uptake at the ecosystem scale because of the prolonged growing season (Euskirchen et al., 2006), although earlier onset possibly results in earlier autumn senescence (Fu et al., 2014b; Keenan and Richardson, 2015). The earlier snow disappearance leads to an earlier decrease in albedo in the spring, resulting in further warming at the regional scale with changes in surface energy exchange (Euskirchen et al., 2007; Ueyama et al., 2014, 2020). 


\section{Conclusions}

We evaluated the species-specific onset of the growing season for three species in interior Alaska using time-lapse cameras and the ecosystem-scale onset of $\mathrm{CO}_{2}$ fluxes. We found that the species-specific onset was explained by the GDD model with a species-specific thermal forcing requirement. The species-specific phenology indicated that careful considerations of species-specific parameters could be necessary for estimating the consequences of spring warming in each plant, although the predicted future change in the onset was unclear because of high uncertainties in climate scenarios. The ecosystem-scale onset was solely explained by the snow disappearance date, which suggested that the snow disappearance date and the onset of the $\mathrm{CO}_{2}$ fluxes were closely linked to each other. This result was possibly because thawing of surface soils immediately after snow disappeared could be important for photosynthesis. The understory contributions before the budburst of the birch decreased with warming spring temperatures, suggesting that the earlier budburst with a shorter day length could increase the regulation of understory production. Under the RCP8.5 scenario, the onset was predicted to be one to three weeks earlier for the three species and five days to a little over 1 month earlier at the ecosystem scale at the end of this century. The future onset is highly sensitive to the snow disappearance date, and hence, we recommend further understanding of climate change during the snowmelting season.

\section{Acknowledgments}

This study was partially supported by the Arctic Challenge for Sustainability (ArCS; JPMXD1300000000) project, and ArCS II (JPMXD1420318865). The eddy covariance data are available from the AmeriFlux database: US-Rpf (https://doi.org/10.17190/AMF/1579540). We thank two anonymous reviewers and the editor for their constructive comments.

\section{References}

Ahrends HE, Etzold S, Kutsch WL et al., 2009: Tree phenology and carbon dioxide fluxes: use of digital photography for process-based interpretation at the ecosystem scale. Climate Research 39, 261-274.

Amiro B, 2010: Estimating annual carbon dioxide eddy fluxes using open-path analysers for cold forest sites. Agricultural and Forest Meteorology 150, 1366-1372.

Barr A, Black TA, McCaughey H, 2009: Climatic and phenological controls of the carbon and energy balances of three contrasting boreal forest ecosystems in Western Canada. In Phenology of Ecosystem Processes (ed. by Noormets, A.). Springer-Verlag, New York, 3-34.

Cannell MGR, Smith RI, 1983: Thermal time, chill days and prediction of budburst in Picea sitchensis. Journal of Applied Ecology, 951-963.

Das S, Suganthan PN, 2010: Differential evolution: A survey of the state-of-the-art. IEEE Transactions on Evolutionary Computation 15, 4-31.

Ettinger AK, Chamberlain CJ, Morales-Castilla I et al., 2020: Winter temperatures predominate in spring phenological responses to warming. Nature Climate Change 10, 1137-1142.

Euskirchen ES, McGuire AD, Kicklighter DW et al., 2006:
Importance of recent shifts in soil thermal dynamics on growing season length, productivity, and carbon sequestration in terrestrial high-latitude ecosystems. Global Change Biology 12, 731-750.

Euskirchen ES, McGuire AD, Chapin III FS, 2007: Energy feedbacks of northern high-latitude ecosystems to the climate system due to reduced snow cover during 20th century warming. Global Change Biology 13, 2425-2438.

Fu Y, Zhang H, Dong W et al., 2014a: Comparison of phenology models for predicting the onset of growing season over the Northern Hemisphere. PLoS ONE 9, e109544.

Fu YS, Campioli M, Vitasse Y et al., 2014b: Variation in leaf flushing date influences autumnal senescence and next year's flushing date in two temperate tree species. Proceedings of the National Academy of Sciences 111, 7355-7360.

Harazono Y, Chikamoto K, Kikkawa S et al., 2009: Applications of MODIS-visible bands index, greenery ratio to estimate $\mathrm{CO}_{2}$ budget of a rice paddy in Japan. Journal of Agricultural Meteorology 65, 365-374.

Helbig M, Wischnewski K, Gosselin GH et al., 2016: Addressing a systematic bias in carbon dioxide flux measurements with the EC150 and the IRGASON open-path gas analyzers. Agricultural and Forest Meteorology 228-229, 349-359.

Hempel S, Frieler K, Warszawski L et al., 2013: A trend-preserving bias correction-the ISI-MIP approach. Earth System Dynamics 4, 219-236.

Holmberg M, Aalto T, Akujärvi A et al., 2019: Ecosystem services related to carbon cycling-modeling present and future impacts in boreal forests. Frontiers in Plant Science 10, 343.

Ide R, Oguma H, 2010: Use of digital cameras for phenological observations. Ecological Informatics 5, 339-347.

Ide R, Nakaji T, Motohka T et al., 2011: Advantages of visible-band spectral remote sensing at both satellite and near-surface scales for monitoring the seasonal dynamics of GPP in a Japanese larch forest. Journal of Agricultural Meteorology 67, 75-84.

Ikawa H, Nakai T, Busey RC et al., 2015: Understory $\mathrm{CO}_{2}$, sensible heat, and latent heat fluxes in a black spruce forest in interior Alaska. Agricultural and Forest Meteorology 214, 80-90.

Ito A, Inatomi M, 2012: Use of a process-based model for assessing the methane budgets of global terrestrial ecosystems and evaluation of uncertainty. Biogeosciences 9, 759-773.

Iwata H, Ueyama M, Harazono Y et al., 2011: Quick recovery of carbon dioxide exchanges in a burned black spruce forest in interior Alaska. SOLA 7, 105-108.

Jarvis P, Linder S, 2000: Constraints to growth of boreal forests. Nature 405, 904-905.

Keenan TF, Richardson AD, 2015: The timing of autumn senescence is affected by the timing of spring phenology: implications for predictive models. Global Change Biology 21, 2634-2641.

Keenan TF, Darby B, Felts E et al., 2014: Tracking forest phenology and seasonal physiology using digital repeat photography: a critical assessment. Ecological Applications 24, 1478-1489.

Kobayashi H, Yunus AP, Nagai S et al., 2016: Latitudinal gradient of spruce forest understory and tundra phenology in Alaska as observed from satellite and ground-based data. Remote Sensing of Environment 177, 160-170.

Leinonen I, Kramer K, 2002: Applications of phenological models to predict the future carbon sequestration potential of 
boreal forests. Climatic Change 55, 99-113.

Melaas EK, Richarson AD, Friedl MA et al., 2013: Using FLUXNET data to improve models of springtime vegetation activity onset in forest ecosystems. Agricultural and Forest Meteorology 171-172, 46-56.

Myneni RB, Dong J, Tucker CJ et al., 2001: A large carbon sink in the woody biomass of Northern forests. Proceedings of the National Academy of Sciences 98, 14784-14789.

Nagai S, Nakai T, Saitoh TM et al., 2013: Seasonal changes in camera-based indices from an open canopy black spruce forest in Alaska, and comparison with indices from a closed canopy evergreen coniferous forest in Japan. Polar Science 7, $125-135$

Piao S, Wang X, Park T et al., 2020: Characteristics, drivers and feedbacks of global greening. Nature Reviews Earth \& Environment 1, 14-27.

Richardson AD, Andy BT, Ciais P et al., 2010: Influence of spring and autumn phenological transitions on forest ecosystem productivity. Philosophical Transactions of the Royal Society B: Biological Sciences 365, 3227-3246.

Suni T, Berninger F, Vesala T et al., 2003: Air temperature triggers the recovery of evergreen boreal forest photosynthesis in spring. Global Change Biology 9, 1410-1426.

Ueyama M, Hirata R, Mano M et al., 2012: Influences of various calculation options on heat, water and carbon fluxes determined by open-and closed-path eddy covariance methods. Tellus B: Chemical and Physical Meteorology 64, 19048.

Ueyama M, Ichii K, Iwata H et al., 2013: Upscaling terrestrial carbon dioxide fluxes in Alaska with satellite remote sensing and support vector regression. Journal of Geophysical
Research: Biogeosciences 118, 1266-1281.

Ueyama M, Ichii K, Iwata H et al., 2014: Change in surface energy balance in Alaska due to fire and spring warming, based on upscaling eddy covariance measurements. Journal of Geophysical Research: Biogeosciences 119, 1947-1969.

Ueyama M, Tahara N, Nagano $\mathrm{H}$ et al., 2018: Leaf- and ecosystem-scale photosynthetic parameters for the overstory and understory of boreal forests in interior Alaska. Journal of Agricultural Meteorology 74, 79-86.

Ueyama M, Iwata H, Nagano H et al., 2019: Carbon dioxide balance in early-successional forests after forest fires in interior Alaska. Agricultural and Forest Meteorology 275, 196-207.

Ueyama M, Yamamori T, Iwata $\mathrm{H}$ et al., 2020: Cooling and moistening of planetary boundary layer in interior Alaska due to a postfire change in surface energy exchange. Journal of Geophysical Research: Atmospheres 125, e2020JD032968.

Vitasse Y, François C, Delpierre N et al., 2011: Assessing the effects of climate change on the phenology of European temperate trees. Agricultural and Forest Meteorology 151, 969-980.

White MA, Running SW, Thornton PE, 1999: The impact of growing-season length variability on carbon assimilation and evapotranspiration over 88 years in the eastern US deciduous forest. International Journal of Biometeorology 42, 139-145.

Xie Y, Civco DL, Silander Jr JA, 2018: Species-specific spring and autumn leaf phenology captured by time-lapse digital cameras. Ecosphere 9, e02089.

Zhang X, Tarpley D, Sullivan JT, 2007: Diverse responses of vegetation phenology to a warming climate. Geophysical Research Letters 34, L19405. 